\title{
Using novel-grass endophyte associations as an avian deterrent
}

\author{
C.G.L. Pennell ${ }^{1}$, M.P. Rolston ${ }^{1,2}$, D. Baird ${ }^{3}$, D.E. Hume ${ }^{4}$, C.M. McKenzie ${ }^{4}$ and S.D. Card ${ }^{4}$ \\ ${ }^{1}$ AgResearch Ltd., Lincoln Research Centre, Private Bag 4749, Christchurch 8140, \\ New Zealand \\ ${ }^{2}$ The Foundation for Arable Research, PO Box 23133, Templeton, Christchurch 8445, \\ New Zealand \\ ${ }^{3}$ VSN (NZ) Ltd., 8 Mariposa Crescent, Aidanfield, Christchurch 8025, New Zealand \\ ${ }^{4}$ AgResearch Ltd., Grasslands Research Centre, Private Bag 11008, Palmerston North 4442, \\ New Zealand \\ Corresponding author: stuart.card@agresearch.co.nz
}

\begin{abstract}
Birds can be major pests in agricultural and horticultural crops as well as being serious hazards to operating aircraft. Cultivars of perennial ryegrass, a hybrid ryegrass and tall fescue, associated with selected Epichloë fungal endophytes were evaluated in aviary and field experiments for their management potential of three nuisance bird species selected as model systems representative of major bird classifications based on their diet. Granivores, namely European green finches, ate more endophyte-free perennial ryegrass seed than endophyteinfected seed, while the representative omnivores, black-backed gulls, avoided endophyteenhanced feed pellets. The selected herbivore, Canada geese, showed an aversion to field trial plots sown with endophyte-infected grass containing ergovaline compared with the existing ground cover. Therefore habitat modification using selected grass-endophyte associations offers an effective wildlife management option aimed at reducing birds in problematic areas.
\end{abstract}

Keywords European green finch (Carduelis chloris), black-backed gull (Larus dominicanus), Canada geese (Branta canadensis), Epichloë, ergovaline.

\section{INTRODUCTION}

Birds can be a major pest in agricultural and horticultural crops, quickly destroying fruit and significantly reducing the harvest of grains and seed. Birds can also be a major nuisance in suburban and urban areas when their populations get too large. For instance, Canada geese (Branta canadensis) can cause damage to lawns located in recreational areas such as sports fields, parks and beaches (Conover \& Chasko 1985), with accumulation of their faeces posing a potential human health risk (Feare et al. 1999; Kullas et al. 2002). One of the most serious effects of birds, however, is the hazards they can create to operating aircraft. Collisions between birds and aircraft, known as bird strike, were responsible for the destruction of over 245 aircraft and the vast majority of the associated 258 human causalities between 1988 and 2014 . These occurrences are becoming more common, with the number of strikes annually reported 
to the Federal Aviation Administration (FAA) increasing 7.4-fold from 1,851 in 1990 to 13,668 in 2014 (Dolbeer et al. 2014).

Wildlife-management practices aimed at reducing bird numbers in problematic areas can be categorised into primary and secondary deterrent mechanisms (Belant \& Martin 2011; Clark \& Avery 2013). Primary mechanisms generally cause birds to have involuntary withdrawal or escape behaviour. Many types, such as acoustic distress calls, dogs, gas guns and lights (Godin 1994; Blackwell \& FernandezJuricic 2013; Seamans et al. 2013), are designed to frighten birds away from a particular area. Secondary mechanisms act by inducing an undesirable physiological effect on birds (Clark 1998; Belant \& Martin 2011), and are generally designed to induce a memory activated aversion response to colour, taste or smell. These include ultraviolet visual cue agents (Werner et al. 2012; Carlson et al. 2013; Esther et al. 2013), contact irritants (Avery et al. 1995; Esther et al. 2013) and poisons (Avery 1984; Linz et al. 2012). In many cases, the primary mechanisms are only a temporary solution (Baxter \& Allan 2008) while secondary mechanisms can have undesirable consequences as many are derivatives of synthetic agricultural pesticides (Dolbeer et al. 1994; Sayre \& Clark 2001). In addition, these methods usually involve significant financial and labour costs, both in set-up and on-going maintenance. Secondary mechanisms also have the obvious problem of allowing at least a pre-emptive attack by birds, and in the case of baits, not all the birds in a population may eat the bait and hence it may take some time before the full deterrent effect is obtained.

Harassment and repellent management solutions should be integrated with habitat management options to reduce the hazardous effects of wildlife at airports (Belant et al. 2013). One habitat-modification strategy is the planting of cool-season grasses infected with fungal endophytes. Many of these associations possess multiple traits that make them an attractive wildlife management option (Washburn et al. 2007). These traits include a wide spectrum of bioactivity that make the grass unpalatable to birds, long-term efficacy and cost effectiveness. Also, such infected grasses possess very few negative wildlife-control aspects such as those affiliated with many conventional methods that cause permanent harm or are lethal. Use of such infected grasses would, therefore, be aligned with practices supported by environmentalists and animal welfare groups. In addition, many countries with climates suitable for the growth of cool-season grasses, generally already utilise a similar form of grass ground cover in settings such as airports, sport and recreational areas and as buffer strips between horticultural crops. Therefore, once the existing vegetation is replaced by the appropriate grass-endophyte association, the usual management regime of nutrient application, irrigation and mowing apply so no new protocols or practices are required.

AgResearch Ltd. has a collection of Epichloë fungal endophyte strains for research and development purposes that have been characterised in terms of genetic diversity and secondary metabolite profiles (Johnson et al.2013). Associations between selected endophyte strains and elite perennial ryegrass (Lolium perenne) cultivars are widely used in New Zealand pastoral farming (Caradus 2013). Considerable variation exists in the alkaloid profiles of these endophyte strains (Tapper \& Latch 1999). Following chemical characterisation, many strains were deemed unsuitable for pastoral use, specifically due to their high levels of ergovaline, a powerful animal toxin (Schardl et al. 2012). However, the presence of this compound (coupled with their capability to produce anti-insect compounds such as peramine and loline alkaloids, (Schardl et al. 2013)) meant that many of these endophyte strains were deemed suitable for wildlife management purposes (Pennell et al. 2010). Use of endophyteinfected cool-season grasses offer a way forward in many areas of wildlife management, being more cost-effective than other methods (Coley et al. 1995). Two combinations of grass and endophyte strain have been developed and marketed under the trade name Avanex ${ }^{\circledR}$ as turf grasses for use in their vegetative form (Pennell et al 2017a, 
b). The objective of this study was to evaluate feeding acceptance by birds offered selected grasses infected with certain endophyte strains. The particular bird species selected for inclusion in this study were chosen as model systems representative of three major bird classifications based on the specific food these birds specialise in eating with the expectation that discoveries made in the model species would provide insight into the responses of related species. European green finches (Carduelis chloris) were chosen as representative of bird species that rely on seed predation (granivores), black-backed gulls (Larus dominicanus) were chosen for their capability to eat plants and small animals (omnivores) while Canada geese were chosen as the representative herbivore, due to their preference for green vegetation, particularly turf grass.

\section{MATERIALS AND METHODS}

\section{Granivorous species}

European green finches were attracted to a granary (Prebble Seeds Ltd., Prebbleton, Canterbury, New Zealand) and humanely trapped in September 2002. Eighty finches were then transferred, and kept for six weeks pre-conditioning, in a custombuilt aviary constructed out of wooden framing and metal cage wire. The entire aviary measured $4.8 \times 3.1 \times 2 \mathrm{~m}$ with a series of separate cages measuring $1.2 \times 1.2 \times 2 \mathrm{~m}$ that were accessed from an internal alleyway that provided additional security when the cages were opened. The eighty finches were fed bird seed (supplied by Prebble Seeds Ltd.) composed mostly of millet, and had access to a continuous supply of fresh water. The birds were separated into two groups of forty and placed into two of the separate cages. Birds that showed signs of stress were released, and 77 birds remained for use in the trial. In the seventh week, endophyte-free tetraploid hybrid ryegrass $(($ L. perenne $\times$ multiflorum $) \times$ perenne $)$ seed, $\mathrm{cv}$. 'Grasslands Greenstone' was introduced into the diet at increasing amounts over a six-week period to condition the birds to this new food source. All capture, handling, and housing methods complied with AgResearch's Animal Ethics Committee standards (AEC no. 552).
After a fasting period of four hours with only water available, eight birds were randomly selected for individual trials and were transferred to individual cages (i.e. one bird per cage) measuring $45 \times 30 \times 45 \mathrm{~cm}$. All sides of each cage were constructed of plywood except the front panel which was constructed of stainless steel 15$\mathrm{mm}$ square mesh to offer the birds light. Eight cages were placed on waist height tables in a row, $5 \mathrm{~cm}$ apart, under cover to provide shade, warmth and protection from rain. Birds in four of the cages were supplied ryegrass seed cv. 'Grasslands Greenstone' infected with the endophyte Epichloë festucae var. lolii strain AR5. The endophyte infection frequency of this seed line was determined to be $>70 \%$ as determined by a seed squash (Latch \& Vaughn 1995) with an ergovaline concentration of $34 \mathrm{ppm}$, determined by highperformance liquid chromatography (Spiering et al. 2002; Spiering et al. 2005). The birds in the remaining four cages were supplied endophytefree seed of 'Grasslands Greenstone'. At the start of the trial, seed (34 g dry weight) was placed at the same time within plastic feeding trays hung on the inside of each cage. After a 20-hour feeding period, the remaining seed was collected and dry weight determined (seed was dried at $80^{\circ} \mathrm{C}$ for $16 \mathrm{~h}$ ). Water was supplied continuously via a bottle mounted inside in each cage. This experiment was conducted three times, using the same birds in each trial. Each trial ran for a total of 20 hours, with a break period of 48 hours between trials; Trial 1 started on 26 November with Trial 3 finishing on 30 November 2002. The entire study period, including the preconditioning phase, lasted 13 weeks. An analysis combining the results for the three trials was carried out using a linear mixed effects model (REML). The fixed effect was Treatment (Endophyte-infected or Endophyte-free) and Trial was the random effect. Due to the small sample sizes, Cohen's D statistic (Walker 2007) for effect size was also determined. Analysis was conducted using GenStat, 18th edition (VSN International Ltd.).

\section{Omnivorous species}

This experiment was conducted at a commercial 
outdoor piggery at Rolleston, Canterbury, New Zealand (43 $33^{\circ} 31^{\prime}$ S; $\left.172^{\circ} 30^{\prime} \mathrm{E}\right)$ where black-backed gulls regularly scavenge on easily obtainable pig-pellets. In early 2002, these birds were identified by the wildlife officers as a potential bird strike hazard at Christchurch International Airport due to the piggery's close proximity to the airport. In April 2002, a circular area ( $25 \mathrm{~m}$ diameter) favoured by the gulls was fenced off from the pigs with an electric fence for 28 days for the purpose of the following investigation. Standard commercially available pig pellets (Takanini Feeds Ltd.) were provided in large concrete troughs $(2 \times 0.5 \times 0.5 \mathrm{~m})$ as a pre-feed to determine acceptance of this newly formed fenced-off area to black-backed gulls. These troughs were moved and randomly placed into different locations within the fenced area before commencement of the trial.

Pig pellets and seed of 'Grasslands Greenstone' ryegrass infected with endophyte strain AR5 were ground in a mill (4:1 ratio) (Thomas Model 4 Wiley $\left.^{\circledR}\right)$ and mixed in a small $159 \mathrm{~kg}$ concrete mixer with a rotation speed of 20-30 rpm. Dough was then made from this ground mix with the addition of warm water and extruded through a caulking gun. After drying in the sun, pellets were shaped from this material to resemble the size, colour and shape of the original pig pellets. A sample of reconstituted pellets was tested for presence and concentration of the alkaloid ergovaline using the extraction and analysis protocols of Spiering et al. (2002), and was found to contain $7.5 \mathrm{ppm}$. Four concrete troughs (dimensions as described above) were set $8 \mathrm{~m}$ apart within the fenced circle. Two troughs were filled with pig pellets containing the endophyteinfected seed and two troughs were filled with the standard pig pellets only. Each morning at $7 \mathrm{am}$, each trough was filled with a fresh $10 \mathrm{~kg}$ of pig pellets with the two types of pellet (with or without endophyte-infected 'Grasslands Greenstone') in the four troughs randomly assigned each day. After each 24-h feeding period, the remaining unconsumed pellets in each trough were weighed. This was repeated for 9 consecutive occasions from the 30 April 2002.
The weight of pellets consumed was analysed using a linear regression model over the 10-day duration with the factor Treatment (endophyteinfected or endophyte-free), conducted using GenStat, 18th edition (VSN International Ltd.).

\section{Herbivorous species}

Canada geese have long been observed in Donnell Park (Christchurch, New Zealand; 43 $29^{\prime} \mathrm{S}$ and $\left.172^{\circ} 41^{\prime} \mathrm{E}\right)$. Here, plots of Avanex ${ }^{\circledR} \mathrm{cv}$. 'Colosseum' perennial ryegrass (infected with the endophyte E. festucae var. lolii strain AR95) and Avanex cv. 'Jackal' tall fescue (Festuca arundinacea Schreb) (infected with the endophyte Epichloë coenophiala strain AR601) were compared with the existing vegetation cover present in the park. Existing vegetation included species such as $L$. perenne, fine fescue grasses (including F. rubra and F. ovina), Poa annua, Vulpia spp. and Dactylis glomerata. There were two plots for each of the three treatments ('Colosseum,' 'Jackal' and existing vegetation), each measuring $20 \times 3.6$ $\mathrm{m}$, arranged in a randomised block design. To prepare the site for sowing, three applications of glyphosate ( $360 \mathrm{~g} /$ litre at a rate of 4 litres/ha) were applied to remove the existing vegetation cover using a boom sprayer. Seed of both Avanex endophyte-grass associations were sown in spring 2008 using an Aitchison Moore uni-drill that had $65 \mathrm{~mm}$ coulter spacing. The existing vegetation plots were left unaltered. The extent of faecal fouling on each plot was determined by counting the number of droppings per plot on two separate occasions (22 May 2009 and 9 July 2009) while grazing intensity was assessed by inspection of the plots with respect to vegetation patchiness, stubble height and proportion of ungrazed plants. Each of these parameters was assigned a score on a scale of 1-5 (where $1=$ laxly defoliated and 5 = intensively defoliated). An analysis combining the results for the two sampling dates was carried out using a linear mixed effects (via REML). The response variables were the grazing-intensity score, and geese droppings. Data were transformed using natural logarithms to stabilise the variance. The fixed effect was Treatment (Jackal AR601; Colosseum 
AR95; Existing vegetation) and Sampling date as the random effect. Analysis was conducted using GenStat, 18th edition (VSN International Ltd.).

\section{RESULTS}

\section{Granivorous species}

Finches consumed significantly $(\mathrm{P} \leq 0.001)$ more (on average 54\%) endophyte-free ryegrass seed than seed infected with the endophyte strain AR5 across the three trials (Figure 1). Finches consumed more than three times as much endophyte-free seed as endophyte-infected seed in Trial 1 and more than twice as much endophyte-free seed in Trials 2 and 3. For each trial, the value of Cohen's D was larger than the large effect size threshold of 0.8 (data not shown), which indicated that the difference between these two groups is large and consistent enough to be important.

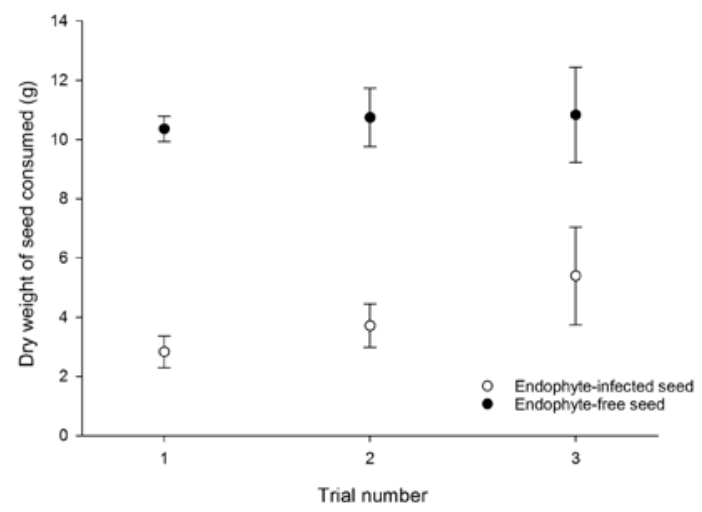

Figure 1 Amount of seed (dry weight in g) ( \pm standard error of mean) consumed by European green finches in a no-choice feeding experiment at set 20 hour feeding periods. There were three separate trials with finches fed hybrid ryegrass 'Grasslands Greenstone' either infected with the Epichloë endophyte strain AR5 (O) or endophytefree $(\bullet)$. Endophyte-infected seed recorded an ergovaline concentration of $34 \mathrm{ppm}$.

\section{Omnivorous species}

Over the 10 feeding days of the trial, gulls consumed on average $8.9 \mathrm{~kg}(89 \%)$ of the endophyte-free pellets and only $4.2 \mathrm{~kg}$ $(42 \%)$ of the pellets containing endophyteinfected seed (Figure 2). The difference in consumption between the two types of pellet was highly significant $(\mathrm{P}<0.001)$ across the entire experimental period. Forty-seven $\mathrm{kg}$ less of the endophyte-infected pellets were consumed than endophyte-free pellets (averaged over all days). The smallest difference in consumption between the two types of pellet occurred on day 4 , with $41.5 \%$ of the endophyte-free pellets consumed compared with $1.5 \%$ of the pellets containing endophyte-infected seed (Figure 2). The greatest difference in consumption between the two types of pellet occurred on day 2, with $100 \%$ of the endophyte-free pellets consumed compared with $17.5 \%$ of the pellets containing endophyteinfected seed (Figure 2).

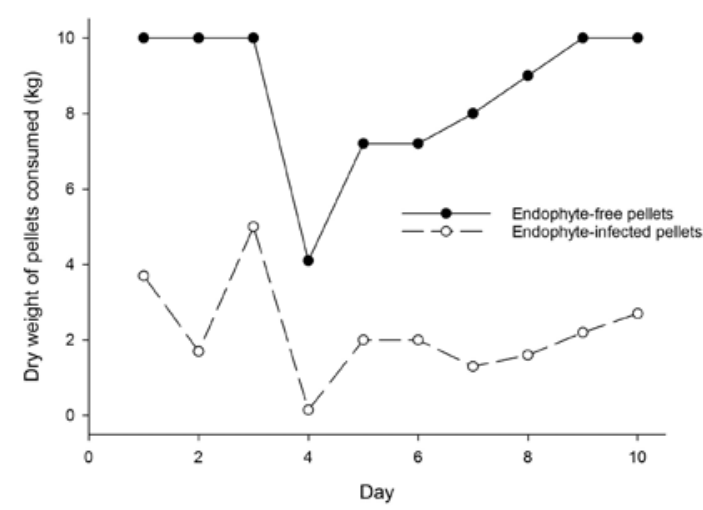

Figure 2 Daily consumption of two types of pig pellets (dry weight in $\mathrm{kg}$ ) by black-backed gulls at an outdoor piggery in 2002 at Rolleston, New Zealand. Pig pellets were supplied with or without endophyte-infected hybrid ryegrass 'Grasslands Greenstone' seed. Pellets containing endophyteinfected seed recorded $7.5 \mathrm{ppm}$ ergovaline. 


\section{Herbivorous species}

Significantly $(\mathrm{P} \leq 0.001)$ more defoliation occurred on the existing vegetation plots (scores of 4.8 for both sampling dates in May and July) compared with either of the grasses infected with endophytes (scores of 2.5 or less) (Figure 3a). These results were mirrored with the faecal assessments where geese left significantly $(\mathrm{P} \leq 0.001)$ more droppings on the existing vegetation plots for both sampling dates, in May and June (Figure 3b). This difference was more pronounced for the first assessment in May where 3 droppings per metre squared were recorded for the existing vegetation plots compared with 0.3 and 0.4 droppings per metre squared for the grass-endophyte associations with 'Colosseum' AR95 and 'Jackal' AR601, respectively (Figure 3b).

\section{DISCUSSION}

European green finches ate less ryegrass seed when it was endophyte-infected, compared with endophyte-free. Conover and Messmer (1996a) reported that zebra finches (Taeniopygia guttata) given endophyte-infected seed consumed less than those birds offered endophyte-free seed in no-choice tests. The use of seeds in the current study demonstrated a behavioural response in

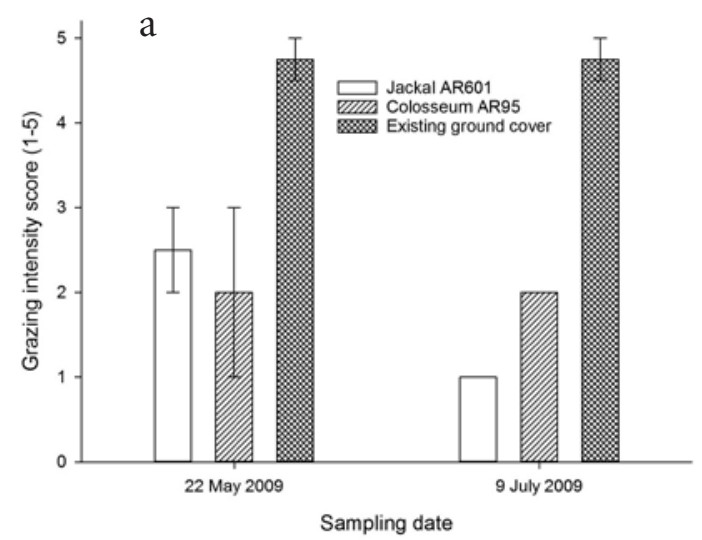

a model species of granivorous bird. Although the currently commercial grass-endophyte products are marketed as a turf grass for use in its vegetative form, this was important to gain valuable information on the underlying mechanism of such products. It was also critical to ascertain any potential negative side effects (i.e. lethal effects) from such a grass product if a bird species were to eat seed, for instance during sowing or if plants within a crop were to fulfil their lifecycle (i.e. from the seed crop).

Black-backed gulls are known to form colony units and this particular colony was observed returning to the piggery on sequential days throughout the trial (P.C. Harper, Christchurch, Canterbury, personal communication). These birds showed a marked learned response when offered the two types of pellet (endophyteinfected vs. endophyte-free). The birds could distinguish between the two types of pellet after the first few days, and actively avoided pellets containing endophyte-infected ryegrass seed for the remaining days of the trial. The use of endophyte-infected ryegrass seed in the form of pellets demonstrated the effectiveness of the active components found in the endophytegrass association and provides some indicative

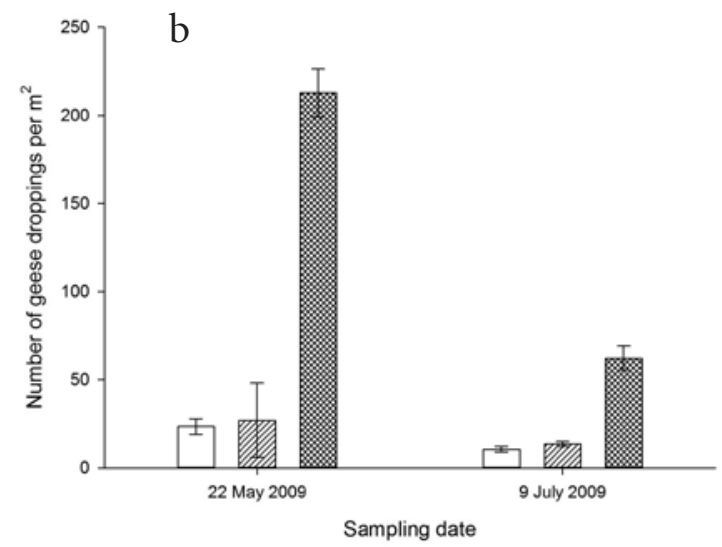

Figure 3 Grazing intensity scores (1-5 scale where $1=$ laxly defoliated and $5=$ intensively defoliated) and dropping counts per metre squared from two sampling dates (22 May 2009 and 9 July 2009) at Donnell Park, Christchurch, New Zealand, with Canada geese exposed to grass-endophyte associations (namely tall fescue 'Jackal' infected AR601 or perennial ryegrass 'Colosseum' infected with AR95) and the existing park vegetation. 
knowledge into the behaviour of related omnivores on exposure to endophyte-derived metabolites. Further investigation would be required to determine if there was a direct application from this finding with regards to repelling granivorous and omnivorous birds from airports, outdoor recreational facilities or other localities. Even though there are no immediate plans to market the product in this fashion, many pelleted baits are available as bird repellents for uses such as in no-till agriculture (Mason et al. 1993).

In 2008, Christchurch City Council staff identified Canada geese as a nuisance in Donnell Park primarily due to damage they were causing by feeding on the existing turf. In addition, accumulation of their faeces was causing a potential health issue. Canada geese showed a significant aversion to plots sown with endophyte-infected grasses in the current study compared with the existing ground cover. The experiment conducted with Canada geese was the only experiment described here that evaluated endophyte products that have since been marketed as Avanex Unique Endophyte Technology.

We speculate that the direct mechanism behind the effective bird deterrence of these novel grassendophyte associations is a chemical defense via secondary metabolites that deter herbivorous animals. This mechanism is one of the oldest and most common ecological interactions, causing a conditioned taste aversion in the target organism (Nicolaus \& Lee 1999) and occurs when an animal associates the taste of a certain food with symptoms caused by a toxic substance. A learned association between an experienced illness and a particular food taste is an extremely powerful behaviour-modifying strategy and can, without constant reinforcement, act as a long-lasting deterrent. If the food source is new to the animal then the learned avoidance to that food can be immediate. However, if the food source is familiar (i.e. in appearance, smell and texture) then repeated exposure to that newly-modified source is generally required in order to alter the learned behavior. This response has been reported for Canada geese (Pennell \& Rolston 2003; Pennell et al. 2010) feeding on certain Epichloë-endophyteinfected grasses, with the behavior termed postingestion feedback (Conover \& Messmer 1996b). This response, from Avanex grasses, has also been evaluated on small mammalian species including mice (Mus musculus) and rabbits (Oryctolagus cuniculus) (Finch et al.2016; Pennell et al. 2017a). The level of deterrence observed in these species is encouraging as small mammals such as invasive rabbits, for example, can have significant unwanted impacts on agriculture and horticulture and can attract birds of prey to airports, increasing the risk of bird strike (Pennell et al. 2017b). These endophyte-grass associations therefore also possess in-direct bird repellent qualities whereby small mammals, the food source of carnivorous and omnivorous bird species, are also deterred by the technology and this in turn reduces the birds that prey on them. In addition, these associations deter many invertebrates that form the diet of many small mammals and insectivorous bird species, including many hazardous/nuisance species, through the production of loline alkaloids, potent insecticidal and invertebrate feeding deterrent compounds (Pennell et al. 2016).

Humans have used wildlife management strategies for thousands of years (Treves et al. 2006), incorporating primary and secondary deterrent mechanisms (Godin 1994; Sayre \& Clark 2001; Shivik et al. 2003; Belant \& Martin 2011). However, the number of registered products and active ingredients for bird control, for example, has declined since the early 1980s in some countries (Sayre \& Clark 2001). The three trials reported here support the use of endophyte-infected grass as a deterrent for granivorous, omnivorous and herbivorous birds.

\section{ACKNOWLEDGEMENTS}

The authors wish to thank the Christchurch City Council for access to Donnell Park, From AgResearch, we thank Brian Tapper for chemical analysis, Anouck de Bonth for technical support and Syd Easton for critical revision of the manuscript. Funding was provided by the Foundation for Arable Research, Grasslanz 
Technology Ltd. and PGG Wrightson Seeds Ltd. Avanex ${ }^{\circledR}$ Unique Endophyte Technology is a registered trademark of PGG Wrightson Seeds Ltd.

\section{REFERENCES}

Avery ML 1984. Relative importance of taste and vision in reducing bird damage to crops with methiocarb, a chemical repellent. Agriculture, Ecosystems \& Environment 11: 299-308.

Avery ML, Decker DG, Humphrey JS, Aronov E, Linscombe SD, Way M 1995. Methyl anthranilate as a rice seed treatment to deter birds. The Journal of Wildlife Management 59: 50-56.

Baxter AT, Allan JR 2008. Use of lethal control to reduce habituation to blank rounds by scavenging birds. The Journal of Wildlife Management 72: 1653-1657.

Belant JL, Martin JA 2011. Principles of avian ecology and biology. Bird harassment, repellent, and deterrent techniques for use on and near airports. Transportation Research Board, Washington, USA. Pp. 6-9.

Belant JL, DeVault TL, Blackwell BF 2013. Conclusions and future directions. In: DeVault TL, Blackwell BF, Belant JL eds. Wildlife in airport environments: preventing animal-aircraft collisions through science based management. Johns Hopkins University Press, Baltimore, USA. Pp. 167-170.

Blackwell BF, Fernandez-Juricic E 2013. Behavior and physiology in the development and application of visual deterrents at airports. In: DeVault TL, Blackwell BF, Belant JL eds. Wildlife in airport environments: preventing animal-aircraft collisions through science based management. Johns Hopkins University Press, Baltimore, USA. Pp. 11-22.

Caradus JR, Lovatt, S and Belgrave, B 2013. Adoption of forage technologies. In: New Zealand Grassland Association, Tauranga, New Zealand, Pp. 39-44

Carlson JC, Tupper SK, Werner SJ, Pettit SE, Santer MM, Linz GM 2013. Laboratory efficacy of an anthraquinone-based repellent for reducing bird damage to ripening corn. Applied Animal Behaviour Science 145: 26-31.
Clark L 1998. Review of bird repellents. In: Proceedings of the Eighteenth Vertebrate Pest Conference, University of Nebraska - Lincoln. Pp. 330-337.

Clark L, Avery ML 2013. Effectiveness of chemical repellents in managing birds at airports. In: DeVault TL, Blackwell BF, Belant JL eds. Wildlife in airport environments: preventing animal-aircraft collisions through science based management. Johns Hopkins University Press, Baltimore, USA. Pp. 25-35.

Coley AB, Fribourg HA, Pelton MR, Gwinn KD 1995. Effects of tall fescue endophyte infestation on relative abundance of small mammals. Journal of Environmental Quality 24: 472-475.

Conover MR, Chasko GG 1985. Nuisance Canada goose problems in the eastern United States. Wildlife Society Bulletin 13: 228-233.

Conover MR, Messmer TA 1996a. Consequences for captive Zebra Finches of consuming tall fescue seeds infected with the endophytic fungus Acremonium coenophialum. The Auk 113: 492-495.

Conover MR, Messmer TA 1996b. Feeding preferences and changes in mass of Canada geese grazing endophyte-infected tall fescue. Condor 98: 859-862.

Dolbeer RA, Avery ML, Tobin ME 1994. Assessment of field hazards to birds from methiocarb applications to fruit crops. Pesticide Science 40: 147-161.

Dolbeer RA, Wright SE, Weller JR, Anderson AL, Begier MJ 2014. Wildlife Strikes to Civil Aircraft in the United States, 19902014 Report of the Associate Administrator of Airports. Office of Airport Safety and Standards. Airport Safety and Certification Federal Aviation Administration. U. S. Department of Agriculture. Animal and Plant Health Inspection Service. Wildlife Services, $101 \mathrm{p}$.

Esther A, Tilcher R, Jacob J 2013. Assessing the effects of three potential chemical repellents to prevent bird damage to corn seeds and seedlings. Pest Management Science 69: 425430. 
Feare CJ, Sanders MF, Blasco R, Bishop JD 1999. Canada goose (Branta canadensis) droppings as a potential source of pathogenic bacteria. The Journal of the Royal Society for the Promotion of Health 119: 146-155.

Finch SC, Pennell CGL, Kerby JWF, Cave VM 2016. Mice find endophyte-infected seed of tall fescue unpalatable - implications for the aviation industry. Grass and Forage Science 71: 659-666.

Godin AJ 1994. Birds at airports. The Handbook: Prevention and Control of Wildlife Damage $56,4 \mathrm{p}$.

Johnson L, de Bonth A, Briggs L, Caradus J, Finch S, Fleetwood D, Fletcher L, Hume D, Johnson R, Popay A, Tapper B, Simpson W, Voisey C, Card S 2013. The exploitation of epichloae endophytes for agricultural benefit. Fungal Diversity 60: 171-188.

Kullas H, Coles M, Rhyan J, Clark L 2002. Prevalence of Escherichia coli serogroups and human virulence factors in faeces of urban Canada geese (Branta canadensis). International Journal of Environmental Health Research 12: 153-162.

Latch GCM, Vaughn DA 1995. Search for seedborne endophytic fungi in rice. International Rice Research Notes 20: 4.

Linz GM, Homan HJ, Werner S, Carlson JC, Bleier

WJ 2012. Sunflower growers use nonlethal methods to manage blackbird damage. Wildlife Damage Management, Internet Center for Publications. University of Nebraska, Lincoln, USA, DigitalCommons. Pp. 114-118.

Mason JR, Clark L, Miller TP 1993. Evaluation of a pelleted bait containing methyl anthranilate as a bird repellent. Pesticide Science 39: 299-304.

Nicolaus LK, Lee H 1999. Low acute exposure to organophosphate produces long-term changes in bird feeding behavior. Ecological Applications 9: 1039-1049.

Pennell C, Rolston M 2003. The effect of grassendophyte associations on feeding of Canada geese (Branta canadensis). In: Proceedings of the New Zealand Grasslands Association, Palmerston North, New Zealand, Pp. 239-243.
Pennell C, Rolston M, de Bonth A, Simpson W, Hume D 2010. Development of a birddeterrent fungal endophyte in turf tall fescue. New Zealand Journal of Agricultural Research 53: 145-150.

Pennell C, Rolston M, Latham A, Mace W, Vlaming J, van Koten C, Latham M, Brown S, Card S 2017a. Novel grass-endophyte associations reduce the feeding behaviour of invasive European rabbits (Oryctolagus cuniculus). Wildlife Research 43: 681-690.

Pennell CGL, Rolston MP, Koten CV, Hume DE, Card SD 2017b. Reducing bird numbers at New Zealand airports using a unique endophyte product. New Zealand Plant Protection 70: 224-234.

Pennell CGL, Popay AJ, Rolston MP, Townsend RJ, Lloyd-West CM, Card SD 2016. Avanex Unique Endophyte Technology - a biological deterrent for the aviation industries. Environmental Entomology 45: 101-108.

Sayre RW, Clark L 2001. Effect of primary and secondary repellents on European starlings: an initial assessment. The Journal of Wildlife Management 65: 461-469.

Schardl CL, Young CA, Faulkner JR, Florea S, Pan J 2012. Chemotypic diversity of epichloae, fungal symbionts of grasses. Fungal Ecology 5: 331-344.

Schardl CL, Florea S, Pan J, Nagabhyru P, Bec S, Calie PJ 2013. The epichloae: Alkaloid diversity and roles in symbiosis with grasses. Current Opinion in Plant Biology 16: 480488.

Seamans TW, Martin JA, Belant JL 2013. Tactile and auditory repellents to reduce wildlife hazards to aircraft. In: DeVault TL, Blackwell BF, Belant JL eds. Wildlife in airport environments: preventing animalaircraft collisions through science based management. Johns Hopkins University Press, Baltimore, USA. Pp. 37-46.

Shivik JA, Treves A, Callahan P 2003. Nonlethal techniques for managing predation: primary and secondary repellents. Conservation Biology 17: 1531-1537. 
Spiering MJ, Lane GA, Christensen MJ, Schmid J 2005. Distribution of the fungal endophyte Neotyphodium lolii is not a major determinant of the distribution of fungal alkaloids in Lolium perenne plants. Phytochemistry 66: 195-202.

Spiering MJ, Davies E, Tapper BA, Schmid J, Lane GA 2002. Simplified extraction of ergovaline and peramine for analysis of tissue distribution in endophyte-infected grass tillers. Journal of agricultural and food chemistry 50: 5856-5862.

Tapper B, Latch G 1999. Selection against toxin production in endophyte-infected perennial ryegrass. Ryegrass endophyte: an essential New Zealand symbiosis. Grassland Research and Practice Series 7: 107-111.
Treves A, Wallace RB, Naughton-Treves L, Morales A 2006. Co-managing human-wildlife conflicts: a review. Human Dimensions of Wildlife 11: 383-396.

Walker I 2007. Statistics for pychology: Making sense of our world through analysis. http:// staff.bath.ac.uk/pssiw/stats2/page2/page14/ page14.html. 20th September

Washburn BE, Loven JS, Begier MJ, Sullivan DP, II HAW 2007. Evaluating commercially available tall fescue varieties for airfields. In: FAA worldwide Airport Technology Transfer Conference Atlantic City, New Jersey, USA, $12 \mathrm{p}$.

Werner SJ, Tupper SK, Carlson JC, Pettit SE, Ellis JW, Linz GM 2012. The role of a generalized ultraviolet cue for blackbird food selection. Physiology \& Behavior 106: 597-601. 